\author{
Витторио С. Томеллери \\ Мачератский университет \\ (Мачерата, Италия) \\ vittorio.tomelleri@unimc.it
}

\title{
ФИЛОЛОГИЧЕСКИЕ ПРОБЛЕМЫ И ЛИНГВИСТИЧЕСКАЯ ИНТЕРПРЕТАЦИЯ ЦИЦЕРОНОВЫХ «ПАРАДОКСОВ» В ПРЕДПОЛАГАЕМОМ ПЕРЕВОДЕ А.М. КУРБСКОГО
}

В третьем послании князя Андрея Михайловича Курбского царю Ивану Грозному, датируемом 1579-м годом, имеется чрезвычайно любопытный перевод двух Цицероновых «Парадоксов стоиков». Славянский текст представляет собой дословную передачу латинского подлинника, точно отражая его порядок слов. В статье предпринимается попытка на основе конкретных примеров выявить некоторые проблемы филологического и лингвистического характера, связанные с пока еще довольно загадочной историей возникновения и распространения этого перевода на Руси.

Ключевые слова: А.М. Курбский, Цицерон, «Парадоксы стоиков», перевод и его бытование.

\section{1. Введение}

Настоящая статья находится на стыке филологии и лингвистики, по мере сил продолжая традиции Андрея Анатольевича Зализняка, всегда умело сочетавшего в своих работах тонкое лингвистическое чутье и математическую строгость изложения при теоретическом обобщении и никогда не терявшего при этом филологическую любовь к конкретным фактам и мелким деталям.

Как известно, изучение древнерусских текстов ставит исследователя перед сложной задачей: ответить на ряд вопросов, касающихся временной и пространственной локализации данного сочинения, его авторства и условий возникновения и дальнейшего распространения. В случае переводных памятников, занимающих львиную долю в древнерусской письменной традиции, ситуация осложняется еще и необходимостью точной идентификации источника, легшего в основу славянского перевода.

В настоящей статье речь пойдет о довольно любопытном древнерусском переводе второго и четвертого «Парадоксов стоиков», составленных римским оратором 
и философом Марком Туллием Цицероном в сложный период его политической и общественной жизни. Славянский текст вошел в состав третьего послания князя Андрея Михайловича Курбского царю Ивану Грозному; в нем попавший в опалу князь доказывает свою невиновность и утверждает, что его вынужденный побег никак не может считаться изменой Родине. Для этой цели Курбский ссылается на идеального предшественника Цицерона, разделившего его тяжкую судьбу изгнания; классический пример из римской истории служит образцом как морального поведения, так и высокого уровня образованности и стилистического преимущества перед соперником:

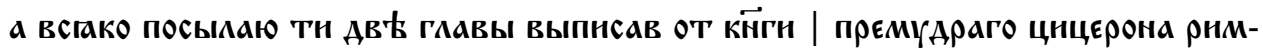

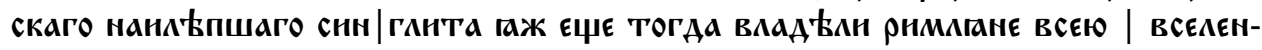

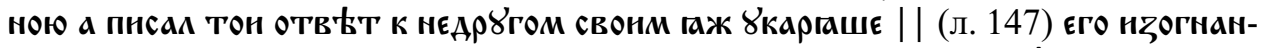

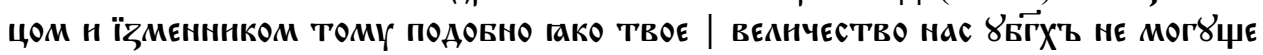

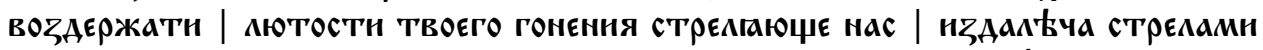

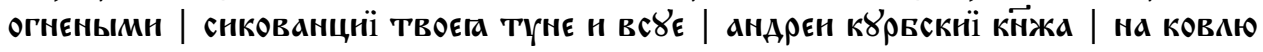
[Ерусалимский 2009, II: 321-322] ${ }^{1}$.

Перед нами стоит ряд проблем, связанных с отождествлением переводчика и суждением о качестве перевода; кроме этого, высказанные гарвардским историком Эдуардом Кинаном сомнения в подлинности переписки Ивана Грозного с Курбским косвенно побуждают к размышлениям и уточнению некоторых не совсем убедительных положений, выдвинутых американским ученым по поводу периферийного характера Цицеронова текста в XVI веке 2 . Кроме того, отсутствие критического издания этого местами неудобопонятного перевода «Парадоксов стоиков» остается до сегодняшнего дня нерешенной проблемой.

${ }^{1}$ Цитаты приводятся по новейшему изданию К. Ю. Ерусалимского [2009, II: 321-333], воспроизводящему точно (буква в букву, строка в строку, лист в лист) основную рукопись ГИМ, Увар. № 301, причем здесь текст дается без подчеркивания и курсива, указывающих на выносные буквы, в том числе с покрытием. Предыдущие издания охватывают длинный временной отрезок, начиная с дореволюционных изданий Н.Г. Устрялова [1868: 205-209] и Г.3. Кунцевича [1914: ст. 137-140] - с латинским оригиналом по парижскому изданию [Cicero 1541] и кончая изданиями Я.С. Лурье и Ю. Д. Рыкова [Переписка 1979: 110-113] и А.И. Филюшкина [2007: 465-475]. В статьях [Tomelleri 2013a: 190-194; 2013b: 52-57] предпринимается попытка осторожного восстановления архетипа на основе интерлинеарного сравнения латинского и славянского текстов. О рукописной традиции «Парадоксов» см. также в работах [Переписка 1979: 250-315; Беляева 1984: 119-120; Ерусалимский 2009, I: 321-332].

2 Пресловутая монография Э. Кинана [Keenan 1971], в которой автор, на основе подробного анализа лишь первого послания Курбского Ивану Грозному, выражал свои сомнения в подлинности переписки, считая её подделкой XVII-го века, стала крупным научным скандалом, вызвавшим бурную и оживлённую дискуссию, в которой приняли участие ведущие советские и зарубежные специалисты, в основном историки по специальности (см., например, статьи [Kappeler 1974; Andreyev 1975; Wójcik 1975; Skrynnikov 1978; Halperlin 1998]). Не будем здесь останавливаться на изложении его аргументов по поводу «Парадоксов стоиков»; во всяком случае, трудно себе представить, чтобы более поздний русский фальсифика(в)тор мог выбрать именно это сочинение и передать его содержание таким смешанным образом. 
Следующие соображения исходят из предварительных исследований немецкого слависта Дитриха Фрайданка, еще в восьмидесятые годы прошлого столетия предложившего методологически правильную постановку вопроса: текст «Парадоксов стоиков» следует изучать в рамках польской гуманистической культуры XVI в. с учетом латинского подлинника, часто дающего ключ для объяснения некоторых особенностей или неправильностей славянского текста. Сам текст содержит многочисленные лексико-синтаксические элементы, указывающие на возможную посредническую роль польской языковой среды, под сильным влиянием которой находился Курбский.

Д. Фрайданк подчёркивал большое расстояние, — более чем сто лет, — лежащее между временем предполагаемого создания перевода и древнейшими сохранившимися списками, существенно ограничивающее возможности текстологического анализа:

„Von der Cicero-Übersetzung, die spätestens 1579 entstanden sein muß, gibt es keine zeitgenössischen Handschriften, weder aus dem westrussischen noch aus dem Moskauer Raum. Zwischen der Entstehung des Textes und den bisher bekannten ältesten Handschriften klafft eine Lücke von 100 Jahren. Das bestimmt die Möglichkeiten unserer Textkritik“ [Freydank 1988: 809].

С полным правом считают, что при переписке синтаксические характеристики обычно переходят из рукописи в рукопись гораздо лучше, чем, например, фонетико-орфографические и морфологические признаки. Следовательно, в этом случае временная дистанция не играет, как правило, определяющей роли:

«Хронологическая дистанция между оригиналом и последующими списками в общем, однако, не мешает изучению синтаксиса, который меньше всего пострадал при копировании» [Ляпон 1971: 129].

В случае «Парадоксов стоиков», однако, мы обнаруживаем как раз противоположную ситуацию, так как именно их синтаксис, первоначально верно отражавший сложную структуру латинских предложений, представляется в существенно искаженном виде. Московские переписчики, не имея перед глазами латинского оригинала, совершенно не справились с непонятным текстом, пестрящим лексическими (и не только) полонизмами, подчиненными синтаксическими конструкциями и своеобразными риторическими фигурами (ablativus absolutus, винительный с инфинитивом, повторы, анафоры и т. п.).

Как уже отмечено, порядок слов славянского перевода почти без исключений ${ }^{3}$ повторяет синтаксические и риторические особенности латинского подлинника, нередко нарушая правила славянского синтаксиса; с другой стороны,

${ }^{3}$ Ср., например, прндван вых во град 328, arcessitus in civitatem sum; мєне коснуттися 328, pervenisse ad me. Другие более «естественные» случаи, как а аз 327, ego vero, иво которон єсть град 327, quae est enim civitas? и нБо нє 327, non igitur не показательны, поскольку здесь следование латинскому словопорядку было невозможно. 
встречающиеся в списках разночтения (отклонения) не затрагивают порядка слов: перед нами случай довольно механической передачи текста.

Отдельно от филологического сравнения списков следует оценивать степень “полонизации” в сочинениях Курбского: в «Парадоксах стоиков» обнаруживается больше полонизмов, чем в самом послании [Freydank 1988: 809]. Стоит задаться двойным вопросом о том, кому принадлежит перевод и существовал ли промежуточный польский перевод, оказавший какое-то влияние на восточнославянскую версию, как она дошла до нас. И, наконец, хотя это не менее значимо, идентификация латинской модели, предполагающая всесторонний анализ славянского текста, является необходимой составляющей при восстановлении последнего.

Этим проблемам и будет посвящено наше изложение, которое указывает возможный путь к осторожной реконструкции первоначального перевода, основанной на внимательном филологическом и лингвистическом анализе обоих текстов. Известно, что Д.С. Лихачев неоднократно предостерегал от любого рода реконструкций архетипа или авторского текста, причем он приводил и аргументы языкового порядка:

«Реконструировать текст, не учитывая возможных его языковых особенностей, свойственных тому времени, к которому исследователь его относит, - значит искусственно создавать текст, который заведомо не мог существовать. Между тем, конечно, реконструкция языка памятника или необходимость учитывать его языковые изменения - самое трудное, что стоит перед каждым реконструктором» [Лихачев 1957: 164].

По поводу того, что «литовское» наследие Курбского обычно рассматривалось в контексте развития русского языка, высказывался с оговоркой издатель Сборника Курбского:

«Этот контекст неудачен, поскольку, как правило, приводит к неразличению языковых реалий Московской Руси и Речи Посполитой второй половины XVI в. и заставляет обходить стороной проблему «полонизмов», которая, как сейчас ясно, затрагивает не только лексику, но и орфографию, грамматику и синтаксис Сборника Курбского. Вместе с тем «литовские» сочинения Курбского заняли устойчивое место в истории московской литературы наравне с его посланиями середины 1560-х годов <...> [Ерусалимский 2009, I: 287].

Здесь следует обратить внимание на лингвистические особенности переводческого сочинения, предположительно свойственные не только другому времени, но и другому культурно-языковому пространству, находящемуся под сильным влиянием польского языка и западной гуманистической культуры. Более того, текст в таком виде, как он представлен в сохранившихся списках, во многих местах невозможно понять, на что указывают не только разные переводы на современные языки [Томеллери 2015], но также факт, что на сайте Института русской литературы (Пушкинский Дом), где помещено полное издание переписки Ивана 
Грозного с Курбским с параллельным переводом на современный русский язык нет ни текста «Парадоксов стоиков», ни его перевода - вместо них, без объяснения, дано троеточие [...]. Текст на самом деле нуждается в очень непростой «хирургической операции» (слова, заимствованные у самого Д. С. Лихачева [1957: 156]), которая, как, впрочем, любая операция, таит в себе известную опасность. Неясность и непонятность перевода, на наш взгляд, являются не только следствием того, что чрезвычайно трудно дословно передать синтаксическую изысканность латинского подлинника, но и результатом искажения самого по себе тяжелого и отчасти запутанного текста со стороны переписчиков. Отдавая себе отчет в гипотетичности подобного восстановления, основанного на сравнении неизвестного оригинала с явно испорченным переводом, мы все-таки с большей долей смелости, чем умелости, вступаем на почву филологических раскопок.

\section{2. Исследуемый материал}

В основе настоящих заметок лежит текст, изданный К. Ю. Ерусалимский [2009], в котором воспроизводится текст основного списка без учета его более или менее явных ошибок. Приведенные в критическом аппарате разночтения по другим спискам, однако, в отдельных случаях позволяют исправить механические ошибки переписчиков; поэтому в ходе изложения мы будем обсуждать архетип и, при необходимости, предлагать осторожную интерпретацию переводческих ошибок. Сравнение разночтений показывает текстологическую важность Тихонравовского списка, которая уже неоднократно отмечалась в литературе 5 .

Издание К. Ю. Ерусалимского выделяется тем, что почти дипломатическое воспроизведение основного списка сопровождается подачей в критическом аппарате всех разночтений, засвидетельствованных в остальных списках. Для латинского текста привлекаются печатные издания конца XV — первой половины XVI в., так как критические издания классической разновидности авторского текста (например [Cicero 2011: 210-215, 220-226]) не содержат текстовые варианты, отраженные в славянском переводе.

\section{1. Оиибки в передаче текста}

В отдельных случаях главный текст, судя по латинскому оригиналу, нуждается в исправлении, которое подсказывают свидетельства других списков, чьи разночтения приведены в критическом аппарате (правильное чтение дается в круглых скобках):

${ }^{4}$ Библиотека литературы Древней Руси. Т. 11: XVI век. СПб., 2001. [http://lib.pushkinskijdom. ru/Default.aspx?tabid=8869 (09.10.2019)].

5 «При этом Тихонравовский список в разночтениях давал представление о более ранней традиции «Истории» и посланий Курбского Ивану Грозному» (Ерусалимский 2009/1: 243, прим. 47), см. также Tomelleri (2013b: 45-46). 
(1) на (ТЯВМСАП ни) сановнтость ни вЊра 323, non gravitas non fides;

(2) Н МЕНЕ ИЗМЕНнНКОМ. ТВОНМ НМганем НАрНЦаєТ (ТВМСАП НарНЦаєШ) 330, et me exulem tuo nomine appellas.

Во многих местах относительно просто, привлекая латинский текст, исправить примеры старательного, но ложного копирования, которые представляют собой явные механические изменения, проникшие в текст в ходе его копирования (Überlieferungsfehler):

(3) Фка н я марн8са вндъХом > а каня марн8са вндъхом 323, Caium vero Marium vidimus [Freydank 1988: 810];

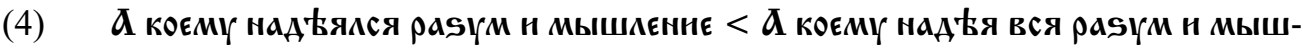
пенне 325, cui spes omnis et ratio et cogitatio [Ibidem].

В трех списках (ЯВМ) действительно засвидетельствовано чтение надњявсга, представляющее собой, по всей видимости, промежуточный этап в цепи: над всга > над Қявсга > наА қяксг.

(5) внснт сшастьг < внснт с щастьг 325, pendet ex fortuna [Idem: 811].

В трех списках (BMC) обнаруживается слитно написанное предложное сочетание сщастья, без следов фонетической ассимиляции. Нельзя пренебрегать тем обстоятельством, что значение латинского слова fortuna здесь, как и на стр. 327 , относится к семантическому полю судьбы или случая.

Еще один лексический «полонизм» имеется в другом пассаже второго парадокса, где лексема мьсто в одном и том же предложении соответствует двум латинским словам, locus и urbs:

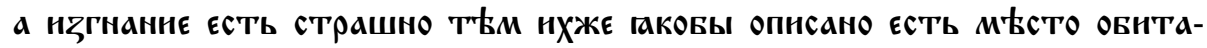

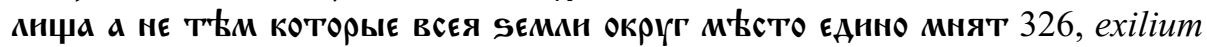
autem est terribile his, quibus quasi circumscriptus est habitandi locus, non his, qui omnem orbem terrarum unam urbem esse ducunt.

(7) АНН КОеГ ПРЕПОАОБНЯ (Т ПрЕПОАОБНе) Н ОБЫчАН ПОХВАМНЫї СУТ ТОГО БЫ ЖНтне непоХвално выло 326, Nec vero cuius virtus moresque laudandi sunt, eius non laudanda vita est.

Предшествующее относительное местоимение в родительном падеже коєг легко могло ввести переписчика в заблуждение.

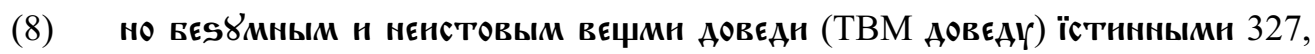
sed dementem et insanum rebus addicam (<adducam?) necessariis.

Это место латинского текста явно повреждено [Неine 1855: 120]. Пробел в средневековье восполнялся по-разному, так что рукописная традиция показывает довольно пеструю картину. Предпочтительная славянская глагольная форма АовєАґ восходит, возможно, к очень редко встречающемуся в рукописной традиции варианту adducam [Cicero 1846: 337] или является просто результатом неправильной интерпретации чтения addicam. 


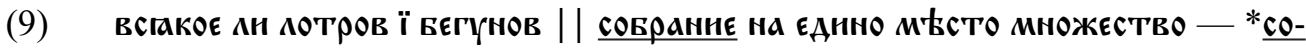
врано 327-328, omnisne enim fugitivorum ac latronum congregata unum in locum multitudo [Freydank 1988: 811];

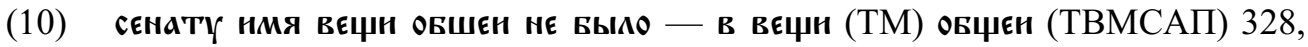
senatus nomen in re publica non erat [Ibidem];

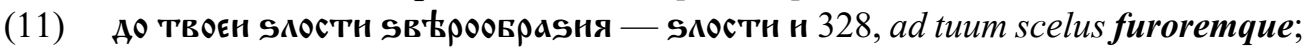

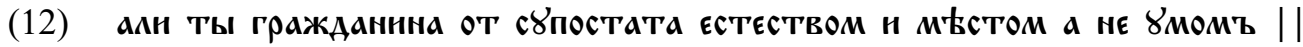

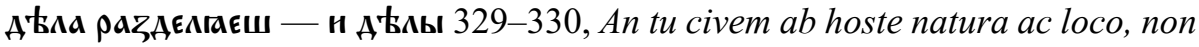
animo factisque distinguis?

\section{2. Переводческие ошибки}

Особо должны трактоваться переводческие ошибки (Übersetzungsfehler), которые часто объясняются дословным подражанием латинскому синтаксису:

(13) ТОМУ ТЫ ЧАВКУ ГРОSН СМЕРТЕН АБО НЗГНАНЕН ПРЕЧЕНМН ЕСАН КОТОРОГО БУАєШ ТАковаго оБряџєШ 325, Eum tu hominem terreto, si quem eris nactus, istiusmodi mortis aut exilii minis (доЛжНо бЫТЬ Просто оБряцєШ ИЛИ БУАєШ оврьк).

Следует здесь отметить морфологически неправильную передачу сложного будущего времени латинского подлинника (eris nactus от глагола nanciscor). Кроме того, здесь нарушается принцип сохранения порядка слов оригинала, так что наречная форма istiusmodi синтаксически поглощается двойной (ошибочной) глагольной формой. Не исключено, что именно морфологическая путаница привела к частичному, хотя бы синтаксически “осмыслительному”, перераспределению слов: «если будешь, найдешь такового».

Что касается передачи латинских относительных предложений и соответсвующих местоименных форм, перед нами следующее распределение:

a) Когда относительное предложение предшествует главному, в котором выступает указательная форма местоимения, переводчик всегда выбирает форму кон:

(14) В КОЕМЪ ПРПАБНЕ ЕСТЬ ТОМУ НнчеСО Ж УБЫВАЕТЪ КО [W]БАЖЕННОМУ 6 ЖНТНЮ 323, In quo virtus sit ei nihil deesse ad beate vivendum;

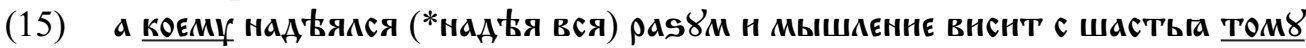

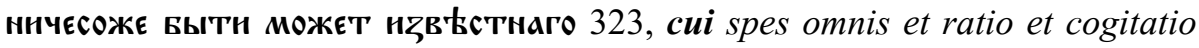
pendet ex fortuna, huic nihil potest esse certi).

б) При обратном порядке (антецедент - относительное местоимение) в функции относительного местоимения выступают как церковнославянская форма нжє, так и более новая которын:

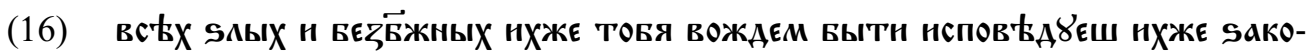
ны нбгнаннем кажненыХ Бытн ХОтят изгнанцы с8ть 330, Omnes scelerati

6 Указанное в аппарате разночтение вㅊєннном૪ предпочтительнее. 
atque impii, quorum tu te ducem esse profiteris, quos leges exilio affici volunt, exules sunt;

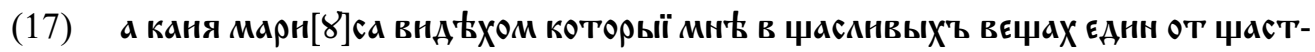
АНВЫХ КЮАЕН А В ПРОТНВНЫХ ЕАНН S НАНВЫШШНХ МУЖЕН ВНАЕАСЯ БЫТН 323, Caium vero Marium vidimus, qui mihi secundis in rebus unus ex fortunatis hominibus, in adversis unus ex summis viris videbatur.

В примере (18) передача придаточного предложения цели содержит множество синтаксически неясных мест:

(18) СМЕРТ АН МН' ГРОБНТ НЖБЫ ЕМ ВОНСТИННУ ОТ АюАЕН || АБО НЪГНАНЕН Аа от SАыХ отшествне БУАєт мн 325-326; лат. Mortemne mihi minitaris, ut omnino ab hominibus, an exilium, ut ab improbis demigrandum sit.

Имя существительное изгнанєн, возможно, стоит в родительном падеже множественного числа по аттракции со стороны предыдущего кюдєн, тогда как соответствующая ему латинская форма exilium выполняет роль прямого дополнения, зависящего от глагола minari. Смущает здесь не совсем понятная форма єм, которая, судя по переводам на современные языки, часто принимается за глагол ятн, так как глагол фсти по смыслу никак не подходит. Можно выдвинуть осторожное предположение о том, что в архетипе здесь стояла западнославянская (польская) комбинация подчинительного союза со связкой в первом лице единственного числа: нжєвым. Дистантная позиция герундивной формы, в конце предложения, способствовала возникновению синтаксической ошибки. В других местах «Парадоксов стоиков» встречаются подобные комбинации союза или отрицания с глаголом быти в настоящем времени:

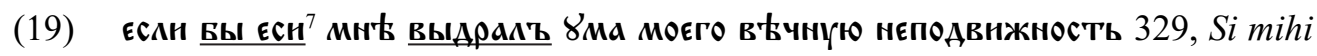
eripuisses divinam animi mei constantiam;

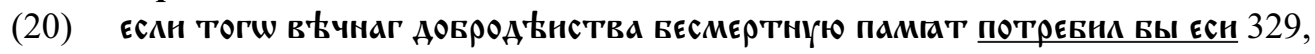
si huius aeterni beneficii immortalem memoriam delevisses;

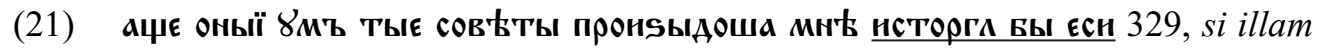
mentem, unde haec consilia manarunt, mihi eripuisses;

(22) Ты акн ніне вонстинну гражданнном ньсть есн 329, Tu ne nunc quidem es civis.

Употребленный дважды ablativus absolutus ошибочно передается простым творительным падежом:

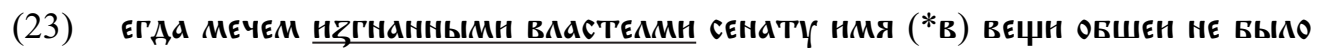
328, cum ferro pulsis magistratibus senatus nomen in re publica non erat;

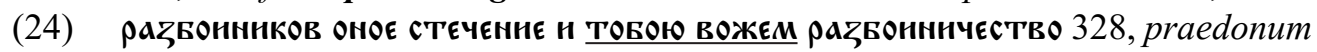
ille concursus et te duce latrocinium.

${ }^{7}$ В списках САП формы єсн нет, скорее всего позднее исправление московского переписчика. 
Иногда трудно сказать, на каком уровне возникла ошибка, при переводе или по вине переписчика архетипа:

смерт мн мн' гроsнт 325, Mortemne mihi minitaris — должно быть гроsнш.

\section{3. Итоги}

Приведенный - хотя еще в отрывочной форме - материал позволяет считать, что любопытный славянский текст «Парадоксов стоиков», дошедший до нас в механически искаженном виде, требует многослойного и разностороннего изучения с целью хотя бы предварительного восстановления утраченного первоначального текста и его возможного подлинника. Только решив поставленную здесь задачу, можно будет разъяснить темные места славянского перевода и продвинуться на пути изучения этой страницы древнерусской письменности, без сомнения, важной с культурной и лингвистической точки зрения.

\section{Источники}

Кунцевич Г.З. Сочинения князя Курбского. Т. І: Сочинения оригинальные. СПб., 1914 (= Русская историческая библиотека. Т. 31).

Переписка 1979 - Я.С. Лурье, Ю.Д. Рыков (подготовили текст). Переписка Ивана Грозного с Андреем Курбским. М., 1979.

Устрялов Н.Г. Сказания князя Курбского. Изд. 3-е, испр. и доп. СПб., 1868 [1833 $]$. [https://reader.digitale-sammlungen.de/resolve/display/bsb10530323.html (22.09.2019)]

Cicero, Marcus Tullius. Bartholomaeus Latomus. Paradoxa, ad Marcum Brurum, cum adnotationibus. Paris, [Jean Loys] apud Jean de Roigny, 1541.

Cicero M. Tullius, De legibus. Paradoxa Stoicorum / Über die Gesetze. Stoische Paradoxien / Lateinisch und deutsch, herausgegeben, übersetzt und erläutert von R. Nickel. Berlin 2011 [Sammlung Tusculum].

Cicero 1846 - M. Tullii Ciceronis Paradoxa, ad codd. mss. partim recens collatorum editionumque veterum fidem recognovit, prolegomena, excerpta scholarum D. Wyttenbachii, annotationem veterum et recentiorum interpretum selectam suamque, excursus et indicem rerum verborumque adiecit Georgius Henricus Moser. Gottingae, 1846.

\section{Литература}

Беляева Н.П. Материалы к указателю переводных трудов А.М. Курбского // Древнерусская литература: источниковедение. Сборник научных трудов / Отв. ред. Д. С. Лихачев. Л., 1984. С. 115-136.

Ерусалимский К.Ю. Сборник Курбского: исследование книжной культуры. T. I-II. M., 2009. 
Лихачев Д. С. К вопросу о реконструкции древнерусских текстов // Исторический архив. 6. 1957. С. 154-166.

Ляпон М. В. Сочинения Курбского - источник для исследования явлений модальности // Русский язык. Источники для его изучения. М., 1971. С. 127-150 [http://www.ruslang.ru/doc/lingistoch/1971/08-ljapon.pdf (22.09.2019)].

Томеллери В. С. Вокруг «Парадоксов» Цицерона в мнимом переводе А. М. Курбского. Проблемы и перспективы // Круги времен. В память Елены Константиновны Ромодановской / Отв. ред. Ромодановская В.А., Силантьев И. В., Титова Л.В. T. 2. М., 2015. С. 233-244.

Филюшкин А.И. Андрей Михайлович Курбский. Просопографическое исследование и герменевтический комментарий к посланиям Андрея Курбского Ивану Грозному. СПб., 2007.

Andreyev N. The Authenticity of the Correspondence between Ivan IV and Prince Andrey Kurbsky // The Slavonic and East European Review. Vol. 53. 1975. No. 133. P. 582-588.

Freydank D. Zwischen griechischer und lateinischer Tradition. A.M. Kurbskijs Rezeption der humanistischen Bildung // Zeitschrift für Slawistik. Bd. 33. 1988. Lfg. 6. S. 806-815.

Halperlin Ch. J. Edward Keenan and the Kurbskii-Groznyj Correspondence in Hindsight // Jahrbücher für Geschichte Osteuropas. Neue Folge, Bd. 46. 1998. Lfg. 3. S. 376-403.

Heine O. Kritische Bemerkungen zu Ciceros Bemerkungen // Philologus. Zeitschrift für das klassische Altertum 10. 1855. S. 116-125.

Kappeler A. Die sowjetische Reaktion auf Keenans Häresie // Jahrbücher für Geschichte Osteuropas. Neue Folge, Bd. 22. 1974. Lfg. 2. S. 187-198.

Keenan E.L. The Kurbskii-Groznyi apocrypha: the seventeenth-century genesis of the «correspondence» attributed to Prince A. M. Kurbskii and Tsar Ivan IV. Cambridge, Mass. 1971.

Skrynnikov R.G. On the Authenticity of the Kurbskii-Groznyj Correspondence: A Summary of the Discussion // Slavic Review. Vol. 37. 1978. No. 1. P. 107-115.

Tomelleri V.S. Il paradosso dei Paradoxa Stoicorum di Cicerone nella presunta traduzione del principe Kurbskij // Contributi italiani al XV congresso Internazionale degli Slavisti / M. Garzaniti et al. (ed.). Firenze, 2013a. P. 157-195.

Tomelleri V.S. Ancora sulla traduzione slavo-orientale dei Paradoxa Stoicorum di Cicerone. Il quarto paradosso // Russica Romana. 20. 2013b. P. 33-57.

Wójcik Zb. Wokół epoki Iwana Groźnego // Kwartlanik Historyczny. R. 82. 1975. Nr. 2. S. 374-403. 


\author{
Vittorio S. Tomelleri \\ Università degli Studi di Macerata \\ (Macerata, Italia) \\ vittorio.tomelleri@unimc.it
}

\title{
PHILOLOGICAL PROBLEMS AND LINGUISTIC INTERPRETATION OF THE TRANSLATION OF CICERO'S "PARADOXES" ATTRIBUTED TO ANDREY KURBSKY
}

The third letter of Prince Andrey Mikhailovich Kurbsky to Tsar Ivan the Terrible, dated 1579, contains an extremely curious translation of two of Cicero's Stoic Paradoxes. The Slavic text is a literal translation of the Latin original, accurately reflecting its word order. The paper aims to identify, using concrete examples, some philological and linguistic problems related to the rather mysterious history of the origin and diffusion of this translation in Russia.

Keywords: A.M. Kurbsky, Cicero, Paradoxa Stoicorum, translation and transmission.

\section{References}

Andreyev N. The Authenticity of the Correspondence between Ivan IV and Prince Andrey Kurbsky. The Slavonic and East European Review. Vol. 53. 1975. No. 133. P. 582-588.

Belyaeva N.P. Materialy k ukazatelyu perevodnykh trudov A.M. Kurbskogo. Drevnerusskaya literatura: istochnikovedenie. Sbornik nauchnykh trudov. Otv. red. D. S. Likhachev. Leningrad, 1984. S. 115-136.

Erusalimskiy K. Yu. Sbornik Kurbskogo: issledovanie knizhnoy kul'tury. T. I-II. Moscow, 2009.

Filyushkin A.I. Andrey Mikhaylovich Kurbskiy. Prosopograficheskoe issledovanie i germenevticheskiy kommentariy k poslaniyam Andreya Kurbskogo Ivanu Groznomu. St. Petersburg, 2007.

Freydank D. Zwischen griechischer und lateinischer Tradition. A.M. Kurbskijs Rezeption der humanistischen Bildung. Zeitschrift für Slawistik. Bd. 33. 1988. Lfg. 6. S. 806-815.

Halperlin Ch. J. Edward Keenan and the Kurbskii-Groznyj Correspondence in Hindsight. Jahrbücher für Geschichte Osteuropas. Neue Folge, Bd. 46. 1998. Lfg. 3. S. 376-403.

Heine O. Kritische Bemerkungen zu Ciceros Bemerkungen. Philologus. Zeitschrift für das klassische Altertum 10. 1855. S. 116-125.

Kappeler A. Die sowjetische Reaktion auf Keenans Häresie. Jahrbücher für Geschichte Osteuropas. Neue Folge, Bd. 22. 1974. Lfg. 2. S. 187-198.

Keenan E. L. The Kurbskii-Groznyi apocrypha: the seventeenth-century genesis of the «correspondence» attributed to Prince A. M. Kurbskii and Tsar Ivan IV. Cambridge, Mass. 1971. 
Likhachev D. S. K voprosu o rekonstruktsii drevnerusskikh tekstov. Istoricheskiy arkhiv, 6. S. 154-166.

Lyapon M.V. Sochineniya Kurbskogo - istochnik dlya issledovaniya yavleniy modal'nosti. Russkiy yazyk. Istochniki dlya ego izucheniya. Moscow, 1971. S. 127-150 [http://www.ruslang.ru/doc/lingistoch/1971/08-ljapon.pdf (22.09.2019)].

Skrynnikov R. G. On the Authenticity of the Kurbskii-Groznyj Correspondence: A Summary of the Discussion. Slavic Review. Vol. 37. 1978. No. 1. P. 107-115.

Tomelleri V.S. Il paradosso dei Paradoxa Stoicorum di Cicerone nella presunta traduzione del principe Kurbskij. Contributi italiani al XV congresso Internazionale degli Slavisti. M. Garzaniti et al. (ed.). Firenze, 2013a. P. 157-195.

Tomelleri V.S. Ancora sulla traduzione slavo-orientale dei Paradoxa Stoicorum di Cicerone. Il quarto paradosso. Russica Romana. 20. 2013b. P. 33-57.

Tomelleri V.S. Vokrug «Paradoksov» Tsitserona v mnimom perevode A.M. Kurbskogo. Problemy i perspektivy. Krugi vremen. V pamyat' Eleny Konstantinovny Romodanovskoy. Otv. red. Romodanovskaya V. A., Silant'yev I. V., Titova L. V. T. 2. Moscow, 2015. S. 233-244.

Wójcik Zb. Wokół epoki Iwana Groźnego. Kwartlanik Historyczny. R. 82. 1975. Nr. 2. S. 374-403. 